\title{
Isoetaceae endémicas del Perú
}

\section{Blanca León 1,2}

${ }^{1}$ Museo de Historia Natural, Av. Arenales 1256, Aptdo. 14-0434, Lima 14, Perú

2 Plant Resources Center, University of Texas at Austin, Austin TX 78712 EE.UU.

blanca.leon@mail.utexas.edu

\section{Resumen}

Entre las familias de las Lycophyta, las Isoetaceae son de fácil reconocimiento por su hábito herbáceo que semeja a una gramínea y por su hábitat palustre o acuático. Esta familia es reconocida en el Perú con un solo género, Isoetes y 10 especies (Hickey, 1994; Smith et al., 2005). Todas las especies, con la excepción de dos, están representadas en la región Altoandina, asociadas a los lagos y bofedales. Cuatro especies son consideradas endemismos para la flora, dos de las cuales son propiamente acuáticas y una es facultativa. Solamente una de estas especies cuenta con poblaciones en un área protegida, si bien amenazas a sus poblaciones son alarmantes (León \& Young, 1996).

Palabras claves: Isoetaceae, Perú, endemismo.

\section{Abstract}

Among Lycophyta families, the Isoetaceae are easily recognized by their herbaceous habit resembling grasses, and by their aquatic or paludicolous life form. This family is recognized in Peru with one genus, Isoetes, and 10 species (Hickey, 1994; Smith et al., 2005). The species, with the exception of two, are represented in the High Andean region, associated with lakes and wetlands. Four species are considered to be endemics, two are submerged aquatics and one is facultative. One endemic species is found within a protected area, although threat to its populations are of concern (León \& Young, 1996).

Keywords: Isoetaceae, Peru, endemism.

\section{Isoetes dispora Hickey}

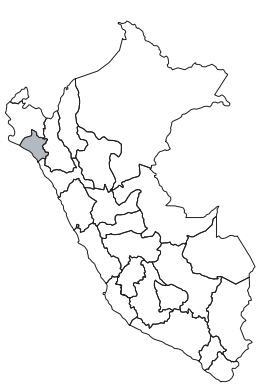

\section{CR, B1ab(iii)}

Publicación: Fieldiana Bot., n.s. 34: 93. 1994.

Colección tipo: A. Sagástegui A. et al. 12850

Herbarios: F, MU; HUT.

Nombre común: Desconocido.

Registro departamental: LA.

Regiones Ecológicas: PAR; $3300 \mathrm{~m}$.

SINANPE: Sin registro.

Herbarios peruanos: HUT (isotipo).

Observaciones: Esta especie acuática, proviene de una de las áreas menos conocidas botánicamente. $\mathrm{Al}$ igual que otras especies en el género, pasan desapercibidas por su hábito y hábitat sumergido. Hickey (1994) señaló el carácter de la presencia de dos tipos de megasporas aunque descartó la posibilidad de un origen híbrido.

\section{Isoetes hewitsonii Hickey}

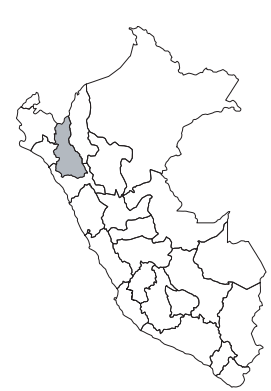

\section{CR, B1ab(iii)}

Publicación: Fieldiana Bot., n.s. 34: 94. 1994.

Colección tipo: I. Sánchez V. 2021

Herbarios: ASU, F, MU; CPUN!.

Nombre común: Desconocido.

Registro departamental: CA.

Regiones Ecológicas: PAR; $3700 \mathrm{~m}$.

SINANPE: Sin registro.

Herbarios peruanos: CPUN (isotipo).

Observaciones: Esta especie acuática, paramuna, sólo se conoce de una localidad y no ha vuelto a ser recolectada desde 1970 . Hickey (1994) postuló que se trate de un poliploide y la necesidad de mayores colecciones y estudios. Lagunas y oconales en la zona están afectados por cambios del drenaje y pastoreo intensivo respectivamente.

\section{Isoetes parvula Hickey}

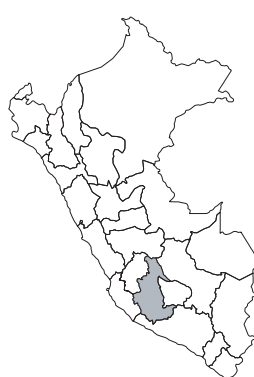

CR, B1ab(iii)

Publicación: Fieldiana Bot., n.s. 34: 92. 1994.

Colección tipo: J. Brandbyge 321

Herbarios: AAU.

Nombre común: Desconocido.

Registro departamental: AY.

Regiones Ecológicas: AA; $4300 \mathrm{~m}$.

SINANPE: Sin registro.

Herbarios peruanos: Ninguno.

Observaciones: Este especie, palustre, se conoce sólo de una localidad, ubicada en una zona con vacío de información botánica; no ha vuelto a ser recolectada desde la década de 1980. Amenazas a sus poblaciones podrían estar asociadas a sequías, cambios climáticos y del paisaje, en este caso el drenaje de lagunas altoandinas.

\section{Isoetes saracochensis Hickey}

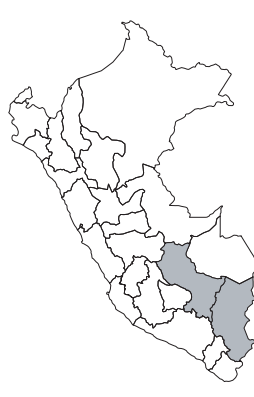

\section{VU, B1ab(iii)}

Publicación: Fieldiana Bot., n.s. 34: 94. 1994.

Colección tipo: T.G. Tutin 1424

Herbarios: BM.

Nombre común: Desconocido.

Registro departamental: CU, PU.

Regiones Ecológicas: PSH, AA; 3950$4200 \mathrm{~m}$

SINANPE: Sin registro.

Herbarios peruanos: Ninguno.

Observaciones: Hierba palustre o acuática que se conoce de cinco localidades, en los alrededores de lagunas, por encima de los 3500 m, en el sur del país. Hickey (1994) menciona las pocas colecciones de herbario que hay para esta especie, carácter que se presenta para toda la flora acuática y humedales del país. Podría estar representada en la flora boliviana. Amenazas potenciales a esta especie provienen de la modificación del hábitat a través de drenaje y represamiento de lagunas; a esto se suma el cambio climático con reducción de lluvias y reducción de glaciares. 